\title{
New audiences for old books: Using astronomy archives in school outreach activities
}

\author{
Siân Prosser $^{1, \star}$ and Sheila Kanani ${ }^{1}$ \\ ${ }^{1}$ Royal Astronomical Society, Burlington House, Piccadilly, London W1J OBQ, United Kingdom
}

\begin{abstract}
The Royal Astronomical Society promotes the study of astronomy and geophysics and has recently committed to increasing public engagement with new audiences. The librarian, Sian Prosser has worked with the outreach, education and diversity officer, Sheila Kanani, to put the scientific archives of the Society at the heart of a primary school workshop telling the story of Caroline Herschel.
\end{abstract}

\section{Introduction}

The Royal Astronomical Society exists to advance, and to record the history of, our understanding of astronomy and geophysics. It does so through various activities, including maintaining a library and archive to preserve its collections and make them accessible to a widening audience, supporting research, education and outreach work. Since 1820 the Royal Astronomical Society has developed a unique collection of books and manuscripts created or donated by its members. The library aims to widen access to its distinctive collections, bringing in new audiences. In particular, the librarian has worked with the outreach officer to devise a school workshop that provides access to primary sources in the RAS archive. The workshop focuses on the life and work of Caroline Herschel, featuring science demonstrations, drama, art and a chance to read the astronomer's handwritten observations.

\section{Caroline Herschel}

Caroline Herschel's remarkable life and achievements made her an ideal focus for a primary school workshop. In 1785 she became the first woman in Britain to receive an annual pension from the King in recognition of her scientific work. King George III granted her the pension for assisting her brother William, which is the work for which she is most often credited, but she made significant contributions of her own to astronomy, discovering eight comets and many more nebulae. In 1828 she was awarded the Gold Medal of the Royal Astronomical Society for her 'unparalleled' cataloguing work, and she and Mary Somerville became the first women to be made honorary members of the Society in 1835 . These were remarkable achievements for a woman who was born in Hanover in 1750 and brought up as her family's unpaid servant before William Herschel arranged for her to live with him in Bath, England, in 1772, where she initially trained as a musician before being drawn into full-time work as her brother's assistant. Caroline Herschel's observation notebooks are now part of the Royal Astronomical Society archive, and play an important role in the primary school workshop.

\footnotetext{
^e-mail: sp@ras.org.uk ORCID: 0000-0002-9610-8678
} 


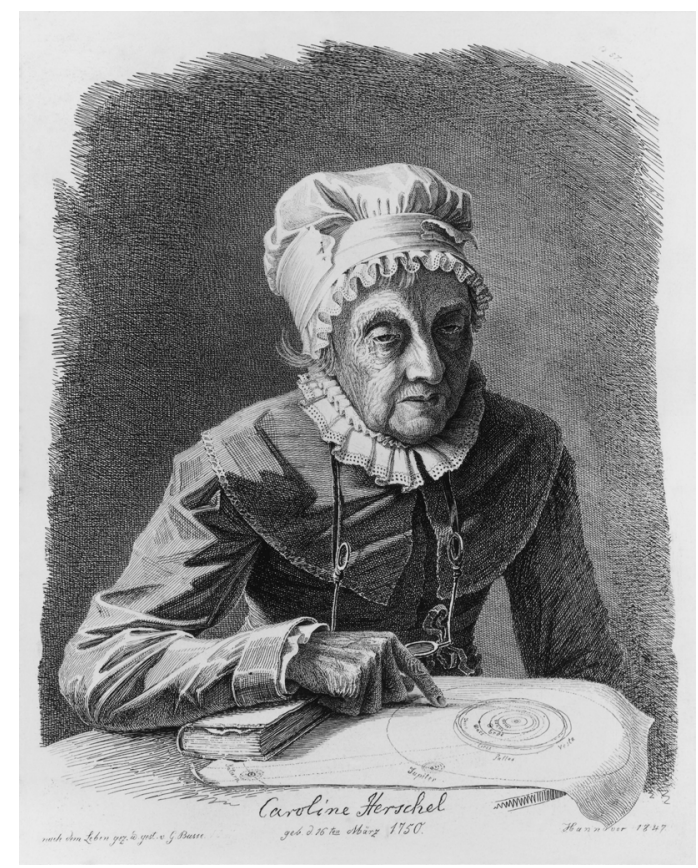

Figure 1. Portrait of Caroline Herschel from 1847.

\section{Workshop format}

\subsection{Science and Drama}

Aimed at students aged 9-11, the visit falls into three parts, each lasting 30 minutes. The RAS building is not large, but it's possible to accommodate a whole year by running all three sessions simultaneously as a carousel of activities on each floor of the building. The outreach officer takes the students on a tour of the solar system, finishing with a dry-ice comet-making demonstration. The students have an audience with Caroline Herschel (played by an actor from Spectrum Drama) who narrates her journey from domestic drudge to musician and scientist. In the library the children look at drawings of William Herschel's telescope, and examine one of the speculum mirrors he made, before turning to Caroline Herschel's observation notebooks.

\subsection{Caroline Herschel's observation notebooks}

The image below shows Caroline's first sighting of what would turn out to be her third comet, now known as Comet C/1790 A1 [1]. The children find her handwriting fairly easy to read out loud, in spite of unfamiliar letters and words. In a group we interpret the text and the image, for example, why is the comet sketched in a circle, and what is the impact of weather on astronomical observations? We then read the rest of the notebook in which Caroline Herschel records the progress of the celestial object, firming up her hypothesis that it is indeed a comet. The children then sketch comets inspired by photographs of Halley's comet dating from 1910, learning more about cometary cycles in the process. 


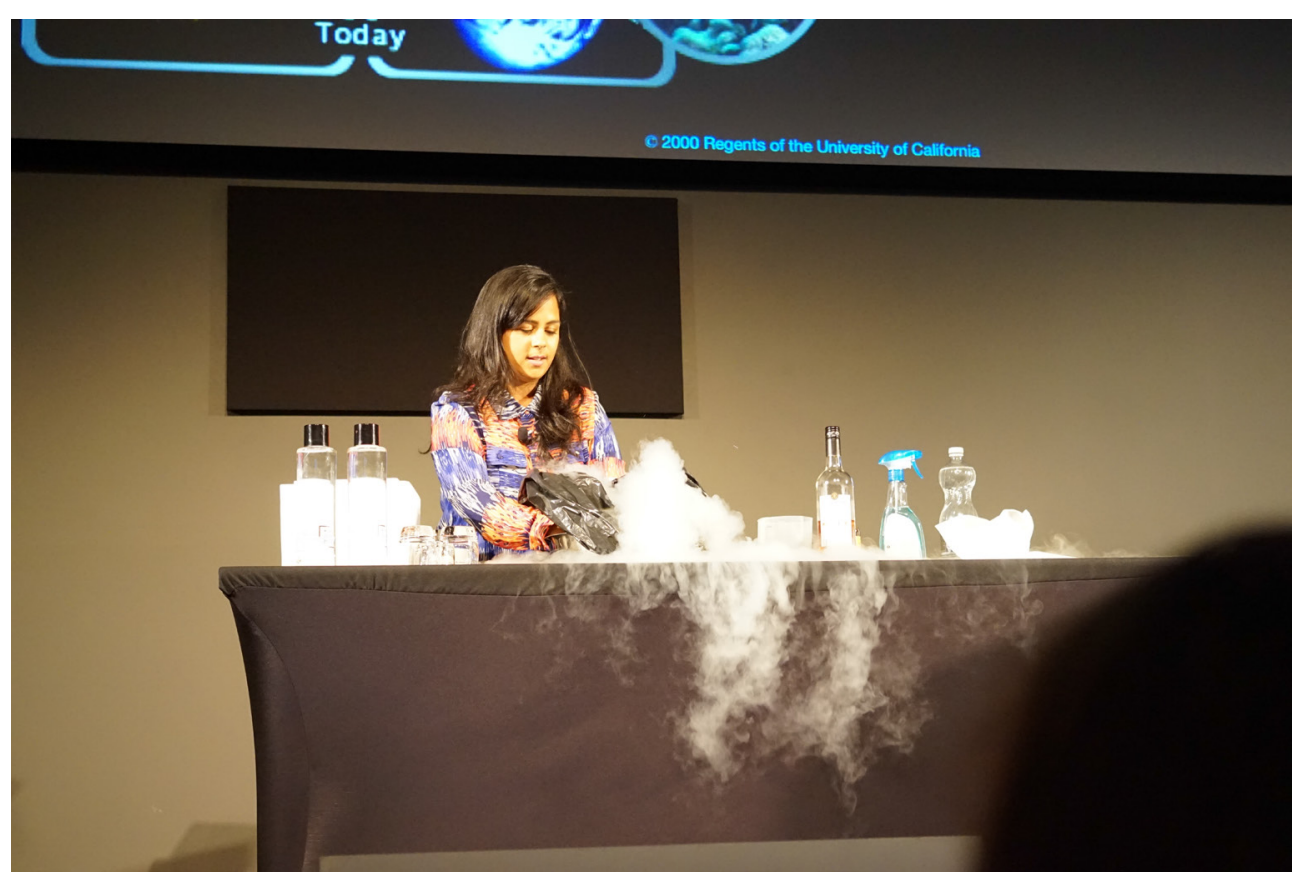

Figure 2. Tour of the solar system and comet-making demonstration.

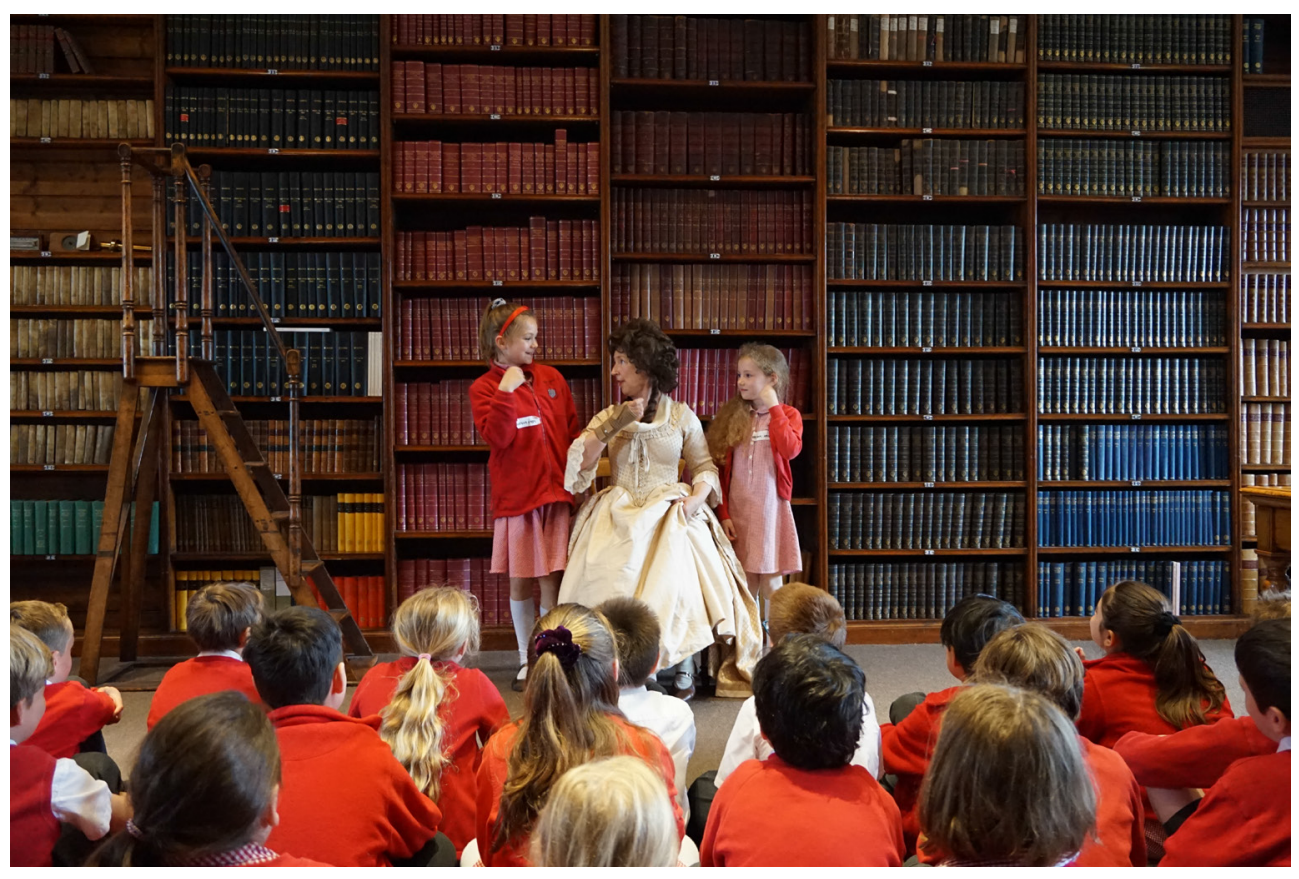

Figure 3. An actor playing the role of Caroline Herschel. 


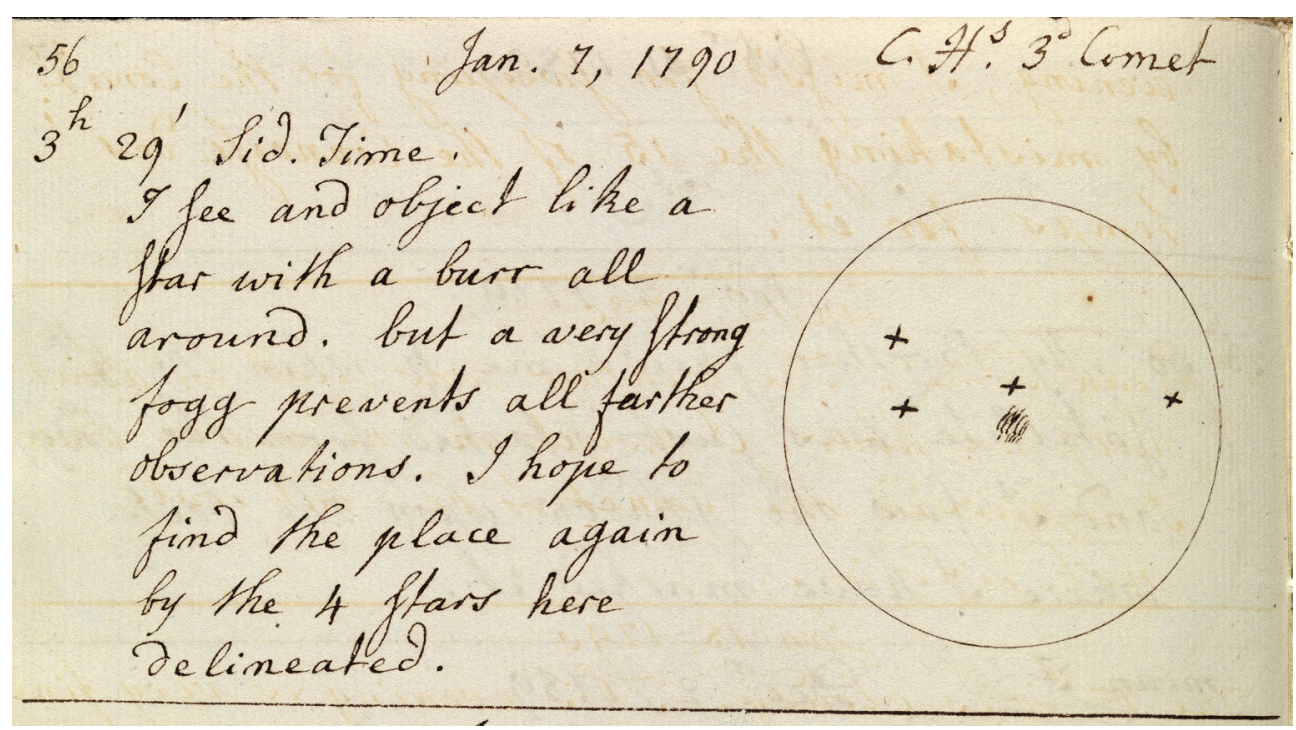

Figure 4. Caroline Herschel's discovery of Comet C/1790 A1 (Herschel) (ref: RAS MSS Herschel C.1/1.2).

\section{Feedback and next steps}

"The activities were hands-on and educational and varied in objective so the children were engaged and learning all the time," according to one teacher. Other feedback from teachers includes the suggestion to make the library activity more challenging by asking children to plot the course of Caroline Herschel's 3rd comet on paper. The librarian and the outreach officer also aim to develop similar workshops based on other astronomers whose fascinating observations, books and instruments can be found in the collections of the Royal Astronomical Society. So far over 250 children have taken part in the workshops, encouraging a passion for astronomy and geophysics using resources that students can't easily access in the classroom, and it is hoped that many more children will be able to take part in future. The RAS is grateful for support from ESERO UK.

\section{Reference}

[1] Caroline Herschel, Book of Observations. From July 7, 1788 to Augt 15, 1797. RAS MSS Herschel C.1/1.2. 